\title{
El desarrollo de las nociones espaciales y temporales
}

\section{The development of spatial and temporal notions in social sciences curricula}

\author{
Alfonso García de la Vega \\ Universidad Autónoma de Madrid
}

\begin{abstract}
Resumen: La adquisición y el dominio de las nociones de espacio y tiempo en el currículum de las Ciencias Sociales se convierten en el eje medular del mismo. De hecho, en las últimas propuestas curriculares, el espacio y tiempo se convierten en conceptos nucleares del proceso de enseñanza-aprendizaje de las áreas afines a las Ciencias Sociales. En este artículo se expone el análisis de las dificultades inherentes a la asimilación de dichas nociones, que arrastra a su vez a otros contenidos del currículum, y se esbozan algunas pautas para establecer un trabajo sistemático.

Palabras clave: Jerarquía conceptual. Currículum. Noción espacial y temporal.

Resumo: A aquisição e domínio dos conceitos de espaço e tempo nos currículos das Ciências Sociais se converteram em importante eixo de análise. De fato, nas últimas propostas curriculares, espaço e tempo tornam-se conceitos nucleares do processo ensino-aprendizagem nas áreas relacionadas com as ciências sociais. Este artigo apresenta a análise das dificuldades inerentes à assimilação dessas noções, que as conecta, por sua vez aos outros conteúdos dos currículos e esboça algumas diretrizes para o estabelecimento de um trabalho sistemático.
\end{abstract}

Palavras-chave: Hierarquia conceitual. Currículo. Noção temporal e espacial.

\begin{abstract}
Learning and the application of spatial and temporal conceptions has turned to be an important element in the syllabus of Social Sciences. In fact, most of recent syllabus proposals have made both space and time core concepts in the teaching/learning process, principally in fields closely linked to Social Sciences. This paper presents an assessment of the inherent difficulties which do arise during the assimilation process of such notions, principally when linked to other curricular contents, and also proposes some guidelines for a systematic approach.
\end{abstract}

Keywords: Conceptual hierarchy. Syllabus. Spatial notion. Temporal notion.

\section{LAS DIFICULTADES DE APRENDIZAJE}

La OCDE (2000, 2003 y 2006) ha establecido indicadores poco precisos sobre el rendimiento de los alumnos, relacionado con aquellos conocimientos y destrezas relativos a los aprendizajes de las Ciencias Sociales. Así, las evaluaciones externas realizadas a los centros educativos muestran resultados sesgados debido a diferentes intereses.

Tal vez, entre las aportaciones más significativas de los resultados de las pruebas, 
se haya constatado la incidencia del factor sociocultural en la valoración de dichos aprendizajes. De este modo, el sesgo resultante puede considerarse definitivo en algunos casos. Precisamente, el postulado sobre la "zona de desarrollo próximo" de Vygotski (2000, p. 130) refuerza la influencia del medio social en el conocimiento. Incluso como medio favorecedor de aprendizajes que como condicionante de los mismos.

En el ámbito psicoevolutivo, Mauri y Valls (2004) exponen que la Geografía ayuda al alumnado a resolver aquellos problemas planteados en un espacio y un tiempo concretos. Por consiguiente, el alumno interrelaciona múltiples elementos que integran esa realidad física y social. Ahora bien, resulta importante el manejo de las fuentes de información y la aplicación de determinadas técnicas de expresión gráfica y cartográfica. Además, a partir de la contribución de las disciplinas de las Ciencias Sociales, el alumno construye una visión crítica, compleja y abstracta de la realidad social.

En todo caso, siguiendo la pauta de la normativa europea (2006), habría que distinguir dos niveles de inclusión de los conocimientos de las Ciencias Sociales en dichas competencias. El primer nivel de competencias corresponde a aquellas estrictamente relacionadas con esta área, como son: "conocimiento e interacción con el mundo físico", "social y ciudadana", "cultural y artística" y "tratamiento de la información y competencia digital". El segundo nivel supone aquellas otras competencias básicas de estrecho vínculo con las Ciencias Sociales por diversas razones -ajenas a los fines de esta reflexión- ("comunicación", "matemática”, , aprender" y "autonomía").

Más aún, si como señala López Martínez (2006) en dos de las ocho competencias básicas, descritas por la directiva de la
Unión Europea (2006), reside el resto de todos los aprendizajes, se observa que los organismos internacionales manifiestan una valoración poco precisa de las Ciencias Sociales.

Ahora bien, si se dejan a un lado, tanto los procesos cognoscitivos como los condicionantes socioculturales vinculados con la construcción del conocimiento para subrayar aquellas dificultades de aprendizaje relacionadas con Geografía e Historia como áreas medulares de las Ciencias Sociales. Aunque, parcialmente, han sido tratados algunos aspectos de estas áreas y desde distintas perspectivas, quizá debamos referirnos al trabajo de Liceras Ruiz (1997), que resuelve una visión psicopedagógica de las dificultades de aprendizaje en las Ciencias Sociales.

\section{ANÁLISIS DEL DESARROLLO DE LA NOCIÓN DEL ESPACIO Y EL TIEMPO}

Hacia la década de los ochenta, la UNESCO (1981, p. 22-25) propuso la descripción y la explicación como el ejercicio intelectual en la Geografía, precisando de un espíritu de observación, memoria e imaginación y, por último, juicio y razonamiento. En definitiva, exponer, explicar y proponer los problemas donde se relacionen el hombre y el medio.

En consecuencia, si se revisan las exigencias descritas en estas competencias se constata que perviven las dificultades de aprendizaje en las áreas de Geografía e Historia y demás disciplinas afines a las Ciencias Sociales. De manera que González García y col. (1995, p. 77 y ss.) demostraron que los conceptos históricos y geográficos no entrañan tanta dificultad como los procedimientos. Así, la relación tiempo-espacio, el comentario de texto, la interpretación de gráficos y el comentario de imágenes mostraron las puntuaciones más bajas en las pruebas realizadas. 
Con todo, en algo más de una década, el torrente de información visual ha transformado la documentación de imágenes y gráficos. Por tanto, el avance en la interpretación gráfico-visual del alumno tal vez haya ido en detrimento de la asimilación de los documentos escritos. En este sentido, quizá el docente deba buscar unos recursos apropiados para el proceso de enseñanza-aprendizaje sin dejar los textos de lado.

Las dificultades de aprendizaje relacionadas con la Geografía se centran en tres ámbitos: la observación y la percepción, el espacio y determinados conceptos. Tanto Bale (1989) como Graves (1997) destacaron el valor de la observación en la Geografía, mientras que Liceras (1997:116) acota la percepción como un paso previo a la observación.

De ahí se derivan algunas dificultades relativas al espacio, tal como afirmó Graves (1997, p. 172), dado que los alumnos muestran mayor dificultad en dibujar un mapa que en leerlo. Ahora bien, el tipo de proyección, la orientación, la escala, la leyenda... son conceptos espaciales y símbolos convencionales para el alumnado, cuyo aprendizaje supone una dificultad vinculada a la madurez cognoscitiva.

No obstante, en dos experiencias realizadas en la década de los setenta, citadas por Graves (1997, p. 144), se muestra que la principal dificultad del alumnado en la lectura de los mapas o las fotografías aéreas residía en establecer una imagen mental del área que encajase con la forma del mapa, según Dale. Y precisamente, Sandford (1972) demostró que los alumnos de secundaria establecen inferencias injustificadas en relación con la lectura de los accidentes geográficos en los atlas, donde la escala es mucho menor.

Asimismo, Gurevich (1998, p. 160) insiste sobre la estructura conceptual de la disciplina para conocer e interpretar el sentido de los procesos actuales en la organización territorial. En este mismo sentido, Liceras (1997, p. 113) subraya el grado de dificultad que poseen determinados conceptos paradigmáticos, en cuanto que se consideran transversales a todas las Ciencias Sociales.

Luego, dichos conceptos permitirían organizar ejes temáticos para la programación de unidades didácticas o de un proyecto determinado. Sin embargo, según Gagné (cit. GRAVES, 1997, p. 153) los conceptos más difíciles de asimilar corresponden a aquellos principios que expresan relaciones de naturaleza abstracta, desligados de la observación directa.

\section{ANÁLISIS DEL DESARROLLO DE LA NOCIÓN DE TIEMPO}

En cuanto a la historia, Liceras (1997, p. 129 y ss.) distingue diversas dificultades de aprendizaje: noción del tiempo, conceptos, causalidad, empatía, contextualización, interpretación, comprensión y valoración. Sobre la noción del tiempo, Pluckrose (1993, p. 33) señala que el concepto de secuencia es el más difícil de asimilar por los alumnos.

Tal vez, la secuencia temporal fuera el embrión del devenir de los cambios históricos, donde se inscribe un concepto histórico crucial, la cronología. En ella, Liceras $(1997$, p. 143) incluye la comprensión de los conceptos de duración y orden. Por su parte, si la causalidad ha fomentado la discusión como paradigma en el estudio de la Historia, Pluckrose (1993, p. 65) ha propuesto estrategias de resolución en la didáctica.

De modo que, el tiempo se puede presentar ajustado a la evolución psicológica del alumno por medio de proponer en el uso de la lengua sencillos conectores del discurso (ayer, hoy, mañana). Dichos conectores pueden permitir a un alumno del 
Primer Ciclo de Primaria establecer una secuencia temporal referida a sus seres más cercanos. La familia constituye un recurso de primer orden para establecer relaciones temporales (abuelos, padrestíos, hermanos-primos).

Dicha secuencia temporal puede adaptarse a la fase psicoevolutiva del alumno, incorporando en breves relatos otros conectores temporales más precisos (en primer lugar, más tarde, luego, después, a continuación, por último). En términos similares se manifiesta Cooper (2002, p. 29), quien además afirma que todo ello contribuye a la adquisición de un vocabulario específico de la Historia.

En los otros dos ciclos de la Etapa Primaria, el alumno puede empezar a ubicar determinados hechos históricos en un friso de la Historia. Herrero Fabregat (2005, p.83 y ss.) explica la división de este friso en en las distintas etapas históricas, donde se pueden incorporar todos aquellos hechos estudiados. Asimismo, el cuadro de doble entrada posibilita relacionar la aparición de unos hechos con sus fechas correspondientes.

De ahí que los contenidos académicos y didácticos no siempre van parejos. En este mismo sentido, Aisenberg (1998, p. 50) define "contenidos pertinentes" como aquellos que mejor pueden favorecer el aprendizaje significativo del alumnado en dirección al objetivo establecido.

Liceras (1997, p.150) define la empatía como la capacidad para comprender otras mentalidades y hábitos de personas que vivieron épocas distintas a las del alumno. La dificultad relativa a contextualizar los hechos históricos reside en evitar primar los hechos en sí mismos y la calificación y clasificación que sobre esos hechos realiza el mismo historiador. Por último, Liceras (1997, p. 153) resalta la dificultad que entraña la descripción, la comprensión e interpretación de los hechos como una evolución lenta y difícil, para posteriormente llevar a cabo una valoración de los mismos.

\section{CONSIDERACIONES FINALES}

En suma, las dificultades de aprendizaje en el área de las Ciencias Sociales muestran tres tipos de condicionantes: la madurez cognoscitiva, el medio sociocultural y la adquisición de unos contenidos previos mínimos. Aunque se han omitido otros factores que inciden en el proceso de enseñanza-aprendizaje, como la participación activa y creativa del docente y la flexibilidad del currículum. Por tanto, en todas sus disciplinas pueden destacarse tres grupos de dificultades de aprendizaje: conceptos y procedimientos específicos a cada disciplina y, por último, aquellos conceptos transversales a todas las disciplinas del área.

\section{REFERENCIAS}

AISENBERG, B. “Un proceso de elaboración de contenidos sobre el tema "Gobierno Nacional" para sexto año de EGB. Hacia la articulación entre los propósitos, los conceptos disciplinares y los conocimientos previos de los alumnos", en AISENBERG, B. y ALDEROQUI, S. (Comp.): Didáctica de las ciencias sociales II. Buenos Aires: Paidós, pp. 43-76,1998. 219 p.

BALE, J. Didáctica de la geografía en la escuela primaria. Madrid: Ediciones Morata y Ministerio de Educación y Ciencia, 1989. 182 p.

COLE, J. P. y BEYNON, N. J. Iniciación a la geografía. (cuadernos y guías del maestro). Barcelona: Fontanella, 1978.

COOPER, H. Didáctica de la historia en la educación infantil y primaria. Madrid: Morata y Ministerio de Educación, Cultura y Deporte, 2002. 263 p.

GRAVES, N. J. La enseñanza de la geografía. Madrid: Visor, 1997. 219 p.

GUREVICH, R. “Conceptos y problemas en Geografía”, pp. 159-182 en AISENBERG, B. y ALDEROQUI, S. (Comp.): Didáctica de las ciencias sociales I, Buenos Aires: Paidós, 1998, 219 p. 
HERRERO FABREGAT, C. Geografía y educación, Madrid: Huerga y Fierro, 1995. 153 p.

LICERAS, A. Dificultades en el aprendizaje de las ciencias sociales. una perspectiva psicodidáctica. Granada: Grupo Editorial Universitario, 1997. 205 p.

LICERAS RUÍZ, Á. Tratamiento de las dificultades en las ciencias sociales. Granada:Grupo Editorial Universitario, 2000.320 p.

LÓPEZ MARTÍNEZ, J. Las competencias básicas del curriculo en la LOE, Congreso Internacional Educación y Sociedad, Granada, Disponivel em http://congreso.codoli.org/ conferencias/ JuanLopez.pdf, 2006. Acesso em 30/11/2007.

MAURI, T. y VALLS, E. “La enseñanza y el aprendizaje de la geografía, la historia y las ciencias sociales: una perspectiva psicológica". en COLL, C.; PALACIOS, J. y MARCHESI, A. (comp.): Desarrollo psicológico y educación. Psicología de la educación escolar 2. Madrid: Alianza Editorial, pp. 509-526, 2004. 719 p.

OCDE Informe PISA (Programa para la Evaluación Internacional de los Alumnos). Madrid: Santillana, 2003. $480 \mathrm{p}$.

PLUCKROSE, H. Enseñanza y aprendizaje de la historia. Madrid: Morata y Ministerio de Educación y Ciencia, 1993. 223 p.

TREPAT, C. A. y COMES, P. El tiempo y el espacio en la didáctica de las ciencias sociales. Barcelona: Graó y Institut de Ciències de l'Educació, Universitat de Barcelona, 2007. 192 p.

UNIÓN EUROPEA Competencias clave para el aprendizaje permanente, Diario Oficial L 394 de 30.12.006.

UNESCO. Método para la enseñanza de la geografía. Barcelona: Teide, 1981. 304 p.

(Recebido em 03/05/2008 e aceito para publicação em $10 / 10 / 2008$ ) 